\title{
L’instabilité politique en Polynésie française
}

\section{Sémir Al Wardi}

\section{(2) OpenEdition \\ Journals}

\section{Édition électronique}

URL : http://journals.openedition.org/echogeo/1990

DOI : 10.4000/echogeo.1990

ISSN : 1963-1197

\section{Éditeur}

Pôle de recherche pour l'organisation et la diffusion de l'information géographique (CNRS UMR 8586)

\section{Référence électronique}

Sémir Al Wardi, «L'instabilité politique en Polynésie française », EchoGéo [En ligne], Sur le Vif, mis en ligne le 03 octobre 2007, consulté le 20 avril 2019. URL : http://journals.openedition.org/ echogeo/1990; DOI : 10.4000/echogeo.1990

Ce document a été généré automatiquement le 20 avril 2019.

\section{(c) (i) (9)}

EchoGéo est mis à disposition selon les termes de la licence Creative Commons Attribution - Pas d'Utilisation Commerciale - Pas de Modification 4.0 International 


\title{
L'instabilité politique en Polynésie française
}

\author{
Sémir Al Wardi
}

1 Le mardi 28 août 2007, soit quelques jours avant l'arrivée du Secrétaire d'Etat chargé de l'Outre-Mer, Christian Estrosi, l'UPLD, la formation politique menée par les indépendantistes, dépose une motion de censure contre le gouvernement Tong Sang, luimême arrivé au pouvoir par une autre motion de censure en décembre 2006. Cette motion de censure n'avait aucune chance d'aboutir, à l'instar de ceux de janvier et juin 2007. Mais, changement majeur dans le paysage politique polynésien, le Tahoeraa Huiraatira, principale formation politique autonomiste, dont le leader est Gaston Flosse, président de la Polynésie près de vingt années, décide d'engager des discussions avec les indépendantistes sur des accords semblables à ceux de Nouméa, baptisés Accords de Tahiti Nui. Rien n'est encore figé, mais cela a permis un rapprochement entre les deux plus grands partis politiques qui ont voté, ensemble, la chute du gouvernement autonomiste de Gaston Tong Sang. Dès lors, la division des autonomistes a entraîné l'élection du leader indépendantiste Oscar Temaru à la tête de l'exécutif polynésien le 13 septembre 2007. Cependant, Christian Estrosi a maintes fois rappelé qu'il présentera rapidement un projet de loi destiné à favoriser la stabilité politique et qui prévoit notamment une abréviation des mandats des représentants à l'assemblée de la Polynésie française. Ainsi, le gouvernement Temaru ne restera en place que trois à quatre mois et devra remettre son mandat en jeu.

2 L'instabilité politique en Polynésie française signifie en quatre ans, sept motions de censure dont quatre menées à terme et une succession de cinq présidents à la tête de l'exécutif polynésien. Pourtant, en quatre ans, il n'y a eu qu'une élection territoriale et une élection partielle. Ainsi, en dehors de toute consultation électorale, les motions de censure sont adoptées parce que certains élus à l'assemblée de la Polynésie française décident de changer de camp et de faire basculer des majorités.

3 La Polynésie a connu une instabilité dès 1945, date du début de la vie politique, marquée essentiellement par des coalitions fragiles ou des renversements de majorité. La seule 
période vraiment stable se situe entre 1996 et 2004. Cette instabilité politique s'explique, notamment, par la culture politique polynésienne dont les caractéristiques sont la faiblesse idéologique et le nomadisme politique.

4 En effet, le statut de la Polynésie française prévoit que seule l'assemblée est élue au suffrage universel direct et que les élus qui, à leur tour, votent pour désigner le président de l'assemblée, son bureau, puis le président de la Polynésie française. Ainsi, le président de la Polynésie française est l'émanation de la majorité à l'assemblée de la Polynésie française. Gaston Flosse résume la situation en affirmant que «l'élection des représentants à l'assemblée de la Polynésie française est incontestablement le scrutin majeur, l'équivalent de ce que sont à la fois les législatives et la présidentielle à l'échelon national $»^{1}$.

5 L'exécutif n'est pas donné à un pouvoir collégial mais à un président de la Polynésie française qui nomme lui-même les ministres à qui il délègue ses pouvoirs. Cette assemblée est souvent accusée d'être une simple chambre d'enregistrement. La docilité de la majorité à l'assemblée territoriale est une constante de la vie politique locale. En revanche, le président de la Polynésie est puissant : c'est lui qui détient tous les leviers du pouvoir, c'est lui qui décide de tout. De plus, il y a une dimension socio-économique du pouvoir : ce dernier, grâce aux transferts de l'Etat et aux compétences accordées, est incontournable dans le jeu économique et social. C'est lui, par exemple, qui distribue les emplois, les subventions, les diverses autorisations et le travail aux entreprises: cette place prépondérante est donc fortement recherchée, disputée.

Plusieurs facteurs peuvent contribuer à une explication de cette instabilité : une vie politique fondée essentiellement sur les relations avec la métropole, une surenchère statutaire, un pouvoir autoritaire qui obtient un mode de scrutin étonnant, le « nomadisme » politique et une lutte pour le pouvoir exacerbée par le clientélisme.

7 En fait, rien ne justifiait qu'à partir de 2004, la vie politique polynésienne soit parsemée de crises politiques: c'est l'œuvre des hommes qui, avec la surenchère statutaire, déstabilisent le jeu politique et gênent le jeu économique dont les partenaires souhaitent une pause statutaire. Le Tahoeraa Huiraatira était de 1996 à 2004, un parti dominant disposant d'une majorité absolue à l'assemblée et d'un appui politique et financier fort de l'Etat. La Polynésie française connaissait une stabilité des institutions. La seule raison de modifier le mode de scrutin et le découpage électoral tient de ce désir de réduire l'opposition à sa plus simple expression, voire de l'écraser ! Car il est évident que selon le mode de scrutin, avec des résultats identiques, un parti politique peut perdre ou gagner les élections! Robert Charvin explique que "accorder le plus de place possible à une certaine opposition au détriment des autres permet au dominant de choisir leurs adversaires et de fabriquer «l'opposition de sa majesté » $»^{2}$. La seule opposition tolérée par le Tahoeraa, mais dans sa plus simple expression, est le Tavini. Une « manipulation », selon les termes même des juristes du Tahoeraa, qui va sauter entre les mains de son initiateur ${ }^{3}$. Le pouvoir passe aux mains d'une coalition autonomistes - indépendantistes avec à sa tête l'indépendantiste Oscar Temaru. Cette coalition, victime d'une motion de censure au bout de trois mois, revient au pouvoir suite à des élections partielles en 2005. Mais retombe en décembre 2006.

8 Le clivage gauche - droite n'existe pas en Polynésie où seul le clivage autonomiste indépendantiste domine. D'abord, essentiellement structuré autour des partisans de l'administration directe de la France et des autonomistes, qualifiés souvent d'indépendantiste, ce clivage devient, dans les années quatre vingt, celui des 
autonomistes et des indépendantistes. C'est ce clivage qui structure la représentation de l'univers politique en Polynésie française. Ainsi, contrairement aux élus des autres collectivités territoriales de la République, les élus polynésiens ne s'inspirent pas des enjeux politiques nationaux : il s'agit évidemment du « développement de la Polynésie française, de la seule politique locale vécue comme nationale $»^{4}$.

Bien sûr, lors des nombreuses crises politiques, ce clivage se brouille avec des coalitions gouvernementales composées d'autonomistes et d'appoint indépendantistes ou inversement : le clivage connaît alors des nuances et même des parenthèses. Toutefois, les élus continuent d'affirmer leur appartenance idéologique même s'ils rejoignent momentanément l'autre camp. Autrement dit, l'obsession de la France oblige les hommes politiques et la population à se définir dans un clivage autonomiste - indépendantiste sans que cela corresponde nécessairement à un choix invariable: l'appartenance idéologique peut fluctuer mais restera immanquablement dans ce rapport à la France.

10 Comme il n'y a aucun prolongement des partis politiques métropolitains ou de leurs idéologies sur ce territoire, la politique n'existe qu'à travers ses propres repères qui relèvent plus de l'affectif, et tourne inlassablement autour de ce pouvoir exogène. C'est donc, au delà même du clivage autonomiste - indépendantiste, la relation avec la métropole qui domine la pensée politique.

11 Les hommes politiques ou l'électorat peuvent passer d'une catégorie à une autre puis inversement et ainsi embrouiller considérablement ce clivage: entre 2004 et 2006, six représentants sur 57 ont changé plusieurs fois de camp. D'ailleurs, ce sont souvent les mêmes personnes qui passent d'une catégorie à l'autre. Les élus polynésiens ont souvent estimé qu'ils étaient libres d'utiliser leur mandat et ainsi de s'associer avec n'importe quel parti politique après leur élection : la culture politique polynésienne donne une relative autonomie aux élus locaux pour négocier, après les élections, leur appartenance à un parti en fonction de leurs intérêts et de celui de leur électorat. Ils seront, en effet, les premiers bénéficiaires de tout changement d'alliance car il vaut toujours mieux pour un élu être dans la majorité pour recevoir en retour ce dont il a besoin pour ses administrés, l'essentiel étant d'être le plus proche possible des ressources publiques afin d'assurer la redistribution.

12 Ainsi, le mode de scrutin et le nomadisme politique favorisent l'instabilité politique en Polynésie française. Mais, notons que cela n'est pas propre à la Polynésie française mais à l'ensemble de l'Océanie: les pays et Etats du Pacifique insulaire connaissent aussi une grande instabilité.

\section{NOTES}

1. Discours de Gaston Flosse au Club 89 et au socio-professionnels du Tahoeraa Huiraatira, le 7 mai 2004.

2. Robert Charvin, La liberté d'expression sous le règne de «l'oppression délicate », Politeia, $\mathrm{n}^{\circ} 9$, 2006, p 119. 
3. Alain Moyrand et Antonino Troianiello (maîtres de conférences de droit public et conseillers juridiques du Tahoeraa), Aspects juridiques de la crise politique polynésienne, Revue Juridique Polynésienne (RJP), volume 11, 2005, p

4. Sémir Al Wardi , Tahiti et la France, le partage du pouvoir, éd. L'Harmattan, Paris, 1998, p XXXX

\section{RÉSUMÉS}

Le mode de scrutin, la faiblesse de l'idéologie et le nomadisme politique favorisent l'instabilité politique en Polynésie française. Mais ce dernier étant un élément de la culture politique polynésienne, la vie politique a connu peu de moment de répit. Le rapprochement soudain des deux principales formations politiques permet le retour du leader indépendantiste au pouvoir.

Electoral system, weakness of ideology et party-switching may account for such an instability in French Polynesia. Party-Switching is an element of the Polynesian political culture: the Polynesian representatives have often thought that they were free to dispose of their mandate as they wished and so, that they could form a partnership with any political party once they had been elected.

\section{INDEX}

Mots-clés : indépendance, Outre-mer, instabilité politique, nomadisme politique, autonomie

\section{AUTEUR}

\section{SÉMIR AL WARDI}

Sémir Al Wardi est Maître de conférences en science politique à l'Université de la Polynésie française. Il a notamment publié : La crise politique en Polynésie française (2004-2005), en collaboration avec Jean-Marc Regnault, /Regards sur l'actualité/, La documentation Française, Paris, n³09, avril 2005 et L'autonomie, un repli sur soi ou une construction de soi ? Ouvrage collectif sous la direction de Bernard Rigo, éd. CNRS, à paraître début 2008. 